\title{
Corporate Leverage and Monetary Policy Effectiveness in the Euro Area*
}

\author{
Simone Auer, Marco Bernardini and Martina Cecioni
}

February 2019

Preliminary and incomplete: please do not circulate without permission

\begin{abstract}
Using country-industry level data and high-frequency identified monetary policy shocks, we find evidence of a positive but non-linear relationship between corporate leverage and the effectiveness of monetary policy in the euro area. More leveraged industries tend to increase their production more strongly after an expansionary monetary policy shock, pointing to a non-negligible role of financial frictions in the transmission mechanism. However, at high leverage ratios this positive relation becomes weaker and eventually inverts. This finding is consistent with recent theoretical studies arguing about the role of credit risk in dampening the financial accelerator channel.
\end{abstract}

JEL classification: C23, E32, E52, G32

Keywords: monetary policy shocks, leverage, euro area, local projections

\footnotetext{
*All authors are affiliated to the Bank of Italy, DG Economics, Statistics and Research. We thank Peter Karadi and Marek Jarociński for providing their series of high frequency monetary policy shocks. All remaining errors are ours. The views expressed in this paper are those of the authors and do not necessarily reflect those of the Bank of Italy or the Eurosystem.
} 


\section{Introduction}

The exact relation between corporate leverage and the responsiveness of firms to a monetary policy shock is still debated in the economic literature. On one hand, corporate leverage is commonly identified as a proxy for the severity of financial frictions. According to the conventional view, more leveraged firms are likely to benefit more from the relaxing of borrowing constraints, thus displaying an amplified sensitivity to a monetary policy shock (Bernanke et al., 1999). On the other hand, the degree of firms' indebtedness is also generally considered as a key determinant of credit risk. In this respect, highly leveraged firms tend to face a steeper marginal cost curve, which dampens their response to a monetary policy shock (Ottonello and Winberry, 2018). Which one of the two theoretical mechanisms prevails is ultimately an empirical matter.

The goal of this paper is to address this question by exploiting the heterogeneity of financial positions across industries and countries in the euro area. Our dataset covers industrial production and firms' balance sheets aggregated at manufacturing two-digit industry level in seven euro area economies, which account for around 85\% of euro area GDP. The country-industry dimension strikes the right balance between the need of having sufficient heterogeneity on corporate financial positions and that of capturing meaningful cross-sectional variations in production. The most recent literature on the effects of monetary policy across firms exploits the granularity of firm's level data (e.g. COMPUSTAT) to address similar questions. In the case of the euro area the use of those data, which do not include information of non-listed companies, would provide a less comprehensive picture of firms' heterogeneity as listed companies are only a small fraction of the population. Furthermore, we would leave out from the analysis those firms that are more likely to be subject to financial frictions.

Our analysis is focused on the euro area as the role of financial heterogeneity for the monetary policy transmission has not been studied as extensively as for U.S. data. The only evidence available is the one provided by Dedola and Lippi (2005) and Peersman and Smets 
(2005) using samples that date back to the years prior to the adoption of the euro. Our baseline specification estimates the responses of industrial production to an high-frequency identified monetary policy shock by means of Jordá's (2005) local projections. We condition the response of output to the leverage ratio of the industry in a given country. ${ }^{1}$ The advantage of this methodology is its flexibility to address the possible non-linearity of impulse responses to monetary policy shocks using both cross-sectional and time-series data. In our specification in particular we test for two degrees of non-linearity: the first is the fact that industries might react differently to monetary policy shocks depending on their leverage ratio (state-dependency); the second is that such state-dependency might be described more effectively as a quadratic function as opposed to a linear one.

Our monetary policy shocks are constructed from high-frequency changes in relevant interest rates around the monetary policy meetings of the Governing Council of the European Central Bank (ECB). This state-of-the-art identification strategy has the benefits to impose a minimal set of restrictions and to be consistent with the presence of possible non-linear effects of monetary policy. To take into account the possibility that market participants reacts to the Governing Council assessment of the economic outlook rather than the policy announcements, we control for information shocks as in Jarociński and Karadi (2018).

We find evidence of a non-linear relation between leverage and the responsiveness of production to monetary policy. Industries with leverage ratios close to $65-70 \%$ are those for which the effects of monetary policy on production is the strongest. Above such levels higher leverage ratios are associated with a lower responsiveness to monetary policy shocks. To give an example, an industry with a leverage ratio of $75 \%$, despite reacting more strongly than an industry with a leverage ratio of $45 \%$, does not adjust its production more aggressively than industries with $65 \%$ leverage ratios. These results are consistent with the existence of a balance sheet channel of monetary policy, but also suggest that such channel is likely to be

\footnotetext{
${ }^{1}$ We focus on the leverage ratio as a measure of how harsh are the financial constraints faced by firms as it is a widely used statistics that collapse the financial structure of an industry. Additional proxies that have been used in the literature are size, liquid assets holdings, age. All of these proxies are usually strongly correlated among them and with leverage ratios.
} 
dampened at high leverage ratios.

The existence of such hump-shaped relation is robust to the use of an alternative two-step estimation strategy in which we first estimate the dynamic response of industrial production to a monetary policy shock in each country-industry pair and then analyze how these responses are associate with leverage ratios in each pair.

Related literature A series of theoretical models derive an heterogeneous response of firms to monetary policy shock depending on their financial situation. The financial accelerator mechanism embedded in Bernanke et al. (1999) implies that high leveraged firms are associated with a higher sensitivity to monetary policy shock. These firms may be financially constrained if their external finance premium is too high to access external funds and cover their financing needs. An unexpected decrease in the policy rate raises the net worth of borrowers, through higher expected cash flows and collateral values. Lowering their expected default probability and relaxing their borrowing constraint, an expansionary monetary policy shock induce firms to raise more funds from external providers and to expand their production.

Ottonello and Winberry (2018) show that the responsiveness to a monetary policy shock could be a non-linear function of firms' leverage. In their model, firms pay a risk premia depending on their financial position. Firms that are highly leveraged, which are financially constrained and have a high default risk, face a steeper marginal cost of capital curve. This constraint makes them less responsive than other financially constrained firms to an exogenous reduction in policy rates (direct effect). At the same time, they are more likely to benefit from the relaxing the borrowing constraint due to changes in cash flows and collateral values (indirect effect). ${ }^{2}$ In their calibration, the former force dominates the latter, implying that the most leveraged firms, being more risky, do not necessarily display the highest sensitivity to monetary policy shocks. Both medium and highly leveraged firms are

\footnotetext{
${ }^{2}$ A financially unconstrained firm has a semi-elasticity of investment with respect to a monetary policy shock which is lower than the one of a financially constrained firm.
} 
nonetheless more responsive than highly capitalized firms. ${ }^{3}$

In Jeenas (2019), the dominance of the direct effects over the indirect ones of monetary policy for firms with a high leverage is more likely to appear only in the very short-run and if the cash flow and collateral channels are relatively muted. In the medium-run, high leveraged firms would unambiguously benefit from the increase in net worth induced by a cut in the policy rate, expanding more their production. ${ }^{4}$

Several empirical papers brought up the evidence in favour of an heterogeneous response of firms to a monetary policy shock depending on their financial position, and leverage ratio in particular. Dedola and Lippi (2005) and Peersman and Smets (2005) find considerable cross-industry heterogeneity in the response to a monetary policy impulse exploiting data on European industries prior to the introduction of the euro. When looking at the role of firms' financial structure, greater sensitivity to policy changes are associated to firms with a higher leverage, a higher proportion of short-term debt over total debt and which are smaller in terms of size. The methodology used in these two papers is based on a two-step procedure. In the first step, impulse response functions are estimated from a structural VAR at the country-industry level. In the second step, the resulting heterogeneity in the responses is explained on the basis of differences in industry characteristics by means of regression analysis.

Over the last few years, a few empirical studies have investigated the heterogeneous response to monetary policy using firm-level data and more recent econometric techniques, similar to the ones used in this paper. In line with his theoretical model, Jeenas (2019) finds that U.S. firms with higher leverage and, especially, lower liquid assets holdings respond

\footnotetext{
${ }^{3}$ A similar conclusion can be obtained in a model with debt overhang. After an exogenous reduction in policy rate, firms that over-borrowed and face high debt service payments may decide to take the opportunity to deleverage and reduce their debt burden. A preference towards balance sheet repair instead of extending their borrowing can therefore dampen the expansionary effect of monetary policy for firms with a high leverage ratio.

${ }^{4}$ Overall, firms with a high leverage ratio may be associated with both a higher or lower sensitivity to monetary policy shocks, depending on various factors. For example, if a highly leveraged firm still has good growth prospects, it may be more responsive to variation in the borrowing costs if it has not yet reached its maximal debt capacity and if it has relatively lower cash holdings, i.e. it cannot use its liquid assets to invest. If instead it already reached its optimal capital stock, then it does not need to extend further its size even if the cost of borrowing decreases.
} 
more to monetary policy shock. Ottonello and Winberry (2018), focusing on a shorter-time horizon, provide a somehow different empirical evidence. Firms with higher debt burdens, a composite proxy of default risk, are found to be less responsive to an unexpected change in the interest rate. Similarly, Cloyne et al. (2018) find that in the United States and in the United Kingdom younger firms with lower leverage or with more liquidity are those which have a significantly higher sensitivity to monetary policy shocks. These firms have a less diversified set of funding sources and their borrowing is highly correlated with asset values but not with earnings.

Structure of the paper The rest of the paper is organized as follows. Section 2 describes the econometric methodology, the data and the identification of the monetary policy shock. Section 3 discusses our empirical results. Finally, section 4 concludes.

\section{Methodology and Data}

\subsection{State-dependent panel local projections}

We analyze how the response of industrial production to a common monetary policy shock depends on leverage by means of Jordá's (2005) local projections (LPs). This method allows to directly compute impulse responses without specifying an underlying multivariate dynamic system, as it is the case in Vector AutoRegressions, making it a very flexible tool to accommodate panel structures and non-linearities. ${ }^{5}$

In the context of our non-linear panel analysis, these advantages appear to be extremely relevant. In particular, recent work by Ottonello and Winberry (2018) has pointed-out that the financial accelerator logic might not apply to over-leveraged firms, due to their higher riskiness, thus suggesting the presence of a potentially complex form of state-dependency that we accommodate by allowing the impulse response to depend quadratically on

\footnotetext{
${ }^{5}$ Other advantages are that LPs do not impose implicit dynamic restrictions on the shape of the impulse response and allow for parsimonious specifications. A disadvantage, however, is that they tend to lose efficiency as the analyzed horizon $h$ from the initial impulse increases.
} 
leverage. More specifically, we estimate the following state-dependent panel local projections:

$$
\begin{aligned}
\sum_{l=0}^{h} \Delta_{l+1} \ln y_{c, s, t+l}= & \alpha^{h}+\beta^{h} \varepsilon_{t}+\sum_{p=1}^{12} \theta^{h p} \Delta \ln y_{c, s, t-p}+ \\
& \ell_{c, s, t-1}\left[\alpha^{L h}+\beta^{L h} \varepsilon_{t}+\sum_{p=1}^{12} \theta^{L h p} \Delta \ln y_{c, s, t-p}\right]+ \\
+ & \ell_{c, s, t-1}^{2}\left[\alpha^{Q h}+\beta^{Q h} \varepsilon_{t}+\sum_{p=1}^{12} \theta^{Q h p} \Delta \ln y_{c, s, t-p}\right]+ \\
& +\alpha_{c}^{h}+\alpha_{s}^{h}+\alpha_{t}^{h}+u_{c, s, t+h}
\end{aligned}
$$

for $h=0, \ldots, H$, where $y_{c, s, t}$ is the production index of the industry $s$ in the country $c$ at time $t, \varepsilon_{t}$ is the high-frequency identified monetary policy shock, $\ell_{c, s, t-1}$ is the predetermined leverage ratio, and $\alpha_{c}^{h}, \alpha_{s}^{h}$, and $\alpha_{t}^{h}$ are a set of fixed effects which capture, respectively, unobserved permanent characteristics within countries, industries, and time periods. ${ }^{6}$ The parameters $\beta^{h}, \beta^{L h}$, and $\beta^{Q h}$ define a relation $\psi^{h}[\ell]$ expressing the cumulative response of industrial production to a common expansionary monetary policy shock at horizon $h$ as a function of corporate leverage $\ell$ :

$$
\psi^{h}[\ell]=\beta^{h}+\beta^{L h} \ell+\beta^{Q h} \ell^{2}
$$

The modelling of the state dependency as a second order polynomial is an elegant and parsimonious way to test the relevance of the analyzed theoretical mechanisms. In particular, a positive linear term $\left(\beta^{L h}>0\right)$ would provide empirical evidence in favour of the traditional balance sheet channel, while a negative quadratic term $\left(\beta^{Q h}<0\right)$ would suggest that this mechanism tends to weaken as the corporate financial structure become more skewed towards debt. To the best of our knowledge our paper is the first study to adopt this non-linear approach in the context of a macroeconomic dynamic model.

\footnotetext{
${ }^{6}$ The shock series $\varepsilon_{t}$ is normalized so that a positive unit value corresponds to a one-standard deviation expansionary monetary policy shock. We specify a predetermined leverage ratio $\ell_{c, s, t-1}$ to avoid the possible contemporaneous influence of the shock on the state-dependent variable itself.
} 
The model includes twelve lags of the monthly growth rate in the industrial production index, which are also assumed to depend quadratically on the leverage ratio. ${ }^{7}$ In all the estimations, we specify Driscoll and Kraay (1998) standard errors, which take into account potential residual cross-sectional correlation, as well as serial correlation and heteroskedasticity among the residuals over time. Finally, to allow for a comparison of the estimates across horizons $h$, we hold the sample constant by using that implied by the longest horizon, which in our analysis is two years $(H=24)$.

Notice that the intercept $\alpha^{h}$ and the parameter $\beta^{h}$ in equation (1) are absorbed by the fixed effects, implying that $\psi^{h}[\ell]$ can only be estimated up to an unidentified constant $\beta^{h}$. This suggests that any quantification of $\psi^{h}[\ell]$ must be carried-out in differential terms, i.e. calculating the rate of change in the effectiveness of a monetary policy shock associated with a difference $\xi$ in the leverage ratio:

$$
\psi^{h}[\ell+\xi]-\psi^{h}[\ell]=\beta^{L h} \xi+\beta^{Q h}\left(\xi^{2}+2 l \xi\right)
$$

In the next section we describe the key data variables in equation (1): the shock series $\varepsilon_{t}$, the output variable $y_{c, s, t}$, and the state dependent variable $\ell_{c, s, t}$.

\subsection{High-frequency identification of monetary policy shocks}

The ECB monetary policy shocks $\varepsilon_{t}$ in model (1) are constructed using a high-frequency identification approach in the spirit of Gürkaynak et al. (2005), Gertler and Karadi (2015), and Jarociński and Karadi (2018). The identification is carried-out in three steps. In the first step, a series of policy announcements surprises is obtained by extracting information from the changes in selected Euro Overnight Index Average (EONIA) swap rates within a fixed time window around monetary policy meetings. The identifying assumptions are that, in the specified time window, (i) no other relevant news affect the EONIA swap rates

\footnotetext{
${ }^{7}$ Notice that, differently from a model in which the identification of the monetary policy shocks is carried-out internally, the use of externally identified shocks implies that lagged controls should not play any major role in the estimation of the structural impulse responses of interest.
} 
and (ii) markets fully incorporate the news released by the ECB. In a second step, the socollected surprises are used to identify a series of monetary policy shocks, as opposed to information shocks. During the press conference that follows the monetary policy meeting, market participants might indeed react to the Governing Council assessment of the economic outlook for the euro area rather than to the release of unexpected monetary news (Nakamura and Steinsson, 2018a). Based on a large class of theoretical models, a policy announcement surprise is considered as a pure monetary policy shock only when there is a negative comovement with the surprise in the equity price index (Jarocinski and Karadi, 2018). ${ }^{8}$ In the third and final step, high-frequency monetary policy shocks are aggregated at the monthly frequency to match with that of our dependent variable.

In this paper we consider two alternative measures of ECB monetary policy shocks. We borrow the first from Jarocinski and Karadi (2018) and derive the second in the spirit of Cecioni (2018). The main difference between the two measures of shocks is the size of the time window: the latter is based on daily intervals, while the measure from Jarociński and Karadi (2018) only reflects intraday movements. ${ }^{9}$ The choice of the time window determines a key trade-off between identification accuracy and statistical power. On one hand, a narrower window maximizes the chances that the identified shocks are truly exogenous. On the other hand, with a wider window, the identified shocks are more likely to have the statistical power to assess their medium-run effects on real variables, such as industrial production, which tend to respond with "long and variable lags" and are affected by many other shocks over the analyzed horizon (Nakamura and Steinsson, 2018b).

The two series also differ over a number of additional dimensions. First, while the time aggregation of intraday-frequency identified shocks is performed by simply summing those belonging to a given month, that of daily-frequency identified shocks is carried-out by

\footnotetext{
${ }^{8}$ Jarociński and Karadi (2018) show that the proportion of "wrong-signed" responses is quite relevant in both the Unites States and the euro area (respectively, 35\% and 45\%) and that ignoring the information shocks strongly biases the results of the standard high-frequency monetary policy identification.

${ }^{9}$ Jarociński and Karadi (2018) uses a 30-minutes window around the press statements and 90 minutes windows around the press conference. In both cases the window starts 10 minutes before the event and 20 minute afterwards. Whenever there is a press conference after the Governing Council meeting, they sum the changes in the two windows.
} 
Figure 1. High-frequency identified ECB monetary policy shocks

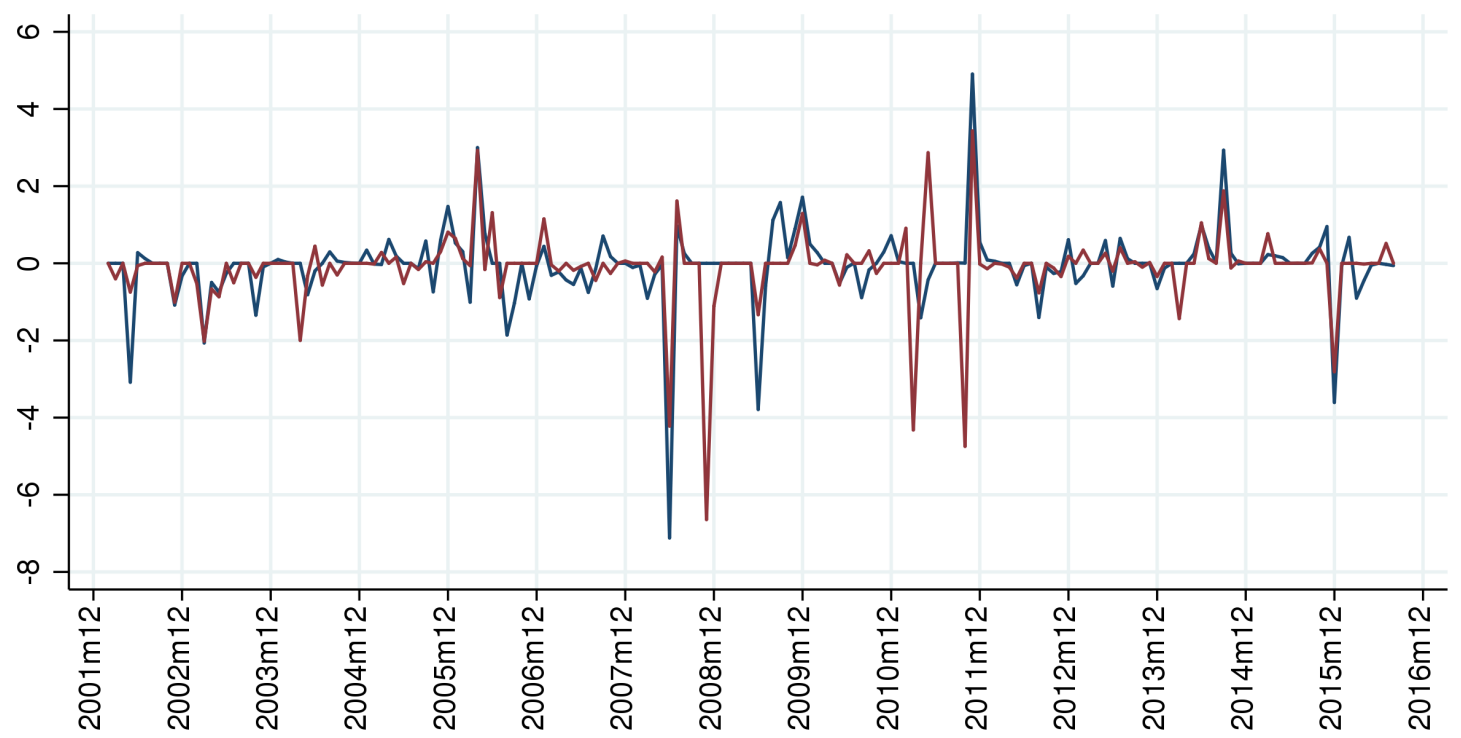

Note. Time-series of the monetary policy shocks identified using daily (blue) and intraday (red) time windows. The series are shown over the actual sample used to estimate model (1) and are normalized so that a positive unit value corresponds to a one-standard deviation expansionary shock.

weighting them by the amount of time industries had to react to them (see Ottonello and Winberry, 2018). Second, the two measures also differ on the dimension over which the communication about future monetary policy is captured. The daily-frequency identified shocks are computed using the first principal component of daily changes of the EONIA swap rates spanning the first year of the term structure, while the intraday-frequency identified shocks exploit 3-months contracts.

Figure 1 plots the two series over the actual sample used in our estimation (1). Both shocks are normalized so that a positive unit value corresponds to a one-standard deviation expansionary shock. Despite capturing roughly the same major unexpected policy announcements, the correlation between the two time-series is only moderately positive $(\rho=0.54)$. In this respect, we will systematically report our results based on both intraday and daily measures, providing further robustness to the empirical findings presented in section 3. 


\subsection{Disaggregated data at country-industry level}

We analyze the effect of a monetary policy shock on variables which vary over time, between countries, and across NACE two-digit industries. Exploiting the wide cross-sectional variation in industry level data can be particularly useful in understanding the effectiveness of monetary policy (Dedola and Lippi, 2005). On one hand, the two-digit level of aggregation is high enough to capture meaningful cross-sectional variation in industrial production and avoid the cost of loosing valuable information along the time dimension, as it is usually the case with firm-level data. On the other hand, it is not too high to loose meaningful cross-sectional variation in corporate finance positions, which tend to vary more among sectors than across countries.

The output variable $y_{c, s, t}$ in model (1) is the seasonally and working-day adjusted monthly index of industrial production sourced by EUROSTAT. The state dependent variable $\ell_{c, s, t}$ is the ratio of total liabilities to total assets sourced by the BACH database. ${ }^{10}$ An industry with a value of $\ell$ equal to $0 \%(100 \%)$ should therefore be considered as being fully capitalized (leveraged), i.e. financed only with equity (debt). ${ }^{11}$ Overall, our dataset covers a sizable cross-section of 7 euro area countries (i.e. Austria, Belgium, Germany, Spain, France, Italy and Portugal) and 22 manufacturing sectors. ${ }^{12}$ The industrial production index is observed monthly in the period 2001m1-2018m8. ${ }^{13}$ The leverage ratio, instead, is available as an end-of-year figure. In order to work with monthly series, we set the first eleven months of a specific year in $\ell_{c, s, t}$ equal to the last month of the previous year (e.g. we set the $2006 \mathrm{~m} 1-2006 \mathrm{~m} 11$ figures equal to the $2005 \mathrm{~m} 12$ figure). In our empirical analysis we also consider an alternative (more structural) definition of leverage, i.e. an

\footnotetext{
${ }^{10}$ The BACH database is constructed by the European Committee of Central Balance Sheet Data Offices (ECCBSO). Balance sheets and income statements of a large number of European non-financial corporations, which are collected at individual level by central banks and government statistical agencies, are aggregated for each unit of observation at annual frequency. The aggregation is based on NACE Revision 2.

${ }^{11}$ Notice that the leverage ratio can also be greater than $100 \%$ when equity is negative.

${ }^{12}$ We exclude "C12 - Manufacture of tobacco products" and "C19 - Manufacture of coke and refined petroleum products" due to lack of data in the BACH and EUROSTAT databases. The missing information is likely to be associated with the limited number of existing firms in these industries.

${ }^{13}$ The presence of leads and lags in model (1) effectively restricts the actual sample to the time interval 2002m2-2016m8.
} 
indicator $\tilde{\ell}_{c, s}$ which exclusively varies across countries and industries. ${ }^{14}$

The BACH database offers key advantages to investigate our research question. First, it can be reliably used to make cross-country comparisons of industries' leverage ratios across several euro area economies. In this respect, a substantial effort had been undertaken to ensure that a large number of firms are used in the aggregation and that the resulting indicators are harmonized across countries notwithstanding differences in national accounting practices (BACH Working Group, 2015). Second, differently from other databases generally used in the literature (i.e. Worldscope and COMPUSTAT), the indicators in the BACH database cover listed as well as non-listed firms, providing a broad and comprehensive assessment of the degree of financial heterogeneity. This is particularly relevant in our analysis since (i) the majority of firms in the euro area are not publicly listed and (ii) privately held firms are likely subject to more severe financial frictions than listed firms. The main drawback in using the $\mathrm{BACH}$ database is that national entities provide coverage ratios of the total population of non-financial corporations which can vary over time. As a result the time variation in $\ell_{c, s, t}$ might partly incorporate the demography of the sample in addition to the population's one. Notwithstanding this limitation, it should be noted that our book-value measure of leverage $\ell_{c, s, t}$ tends to evolve slowly over time and that the bulk of the variation comes from the cross-section. In addition, the above-mentioned use of a more structural state-dependent variable $\tilde{\ell}_{c, s}$ provides a simple robustness check to assess the relevance of this issue.

\section{Empirical results}

In this section we document the presence of a positive but non-linear empirical relation between corporate leverage and monetary policy effectiveness in the euro area. Given a common monetary policy shock, we find that more leverage tends to be associated with a greater responsiveness of industrial production. At high leverage ratios, however, this

\footnotetext{
${ }^{14}$ In particular, $\tilde{\ell}_{c, s}$ denotes the median leverage ratio over time in a given country-industry bin. The use of the median value is intended to minimize the incidence of the time variation.
} 
Figure 2. Quadratic relation between corporate leverage and monetary policy
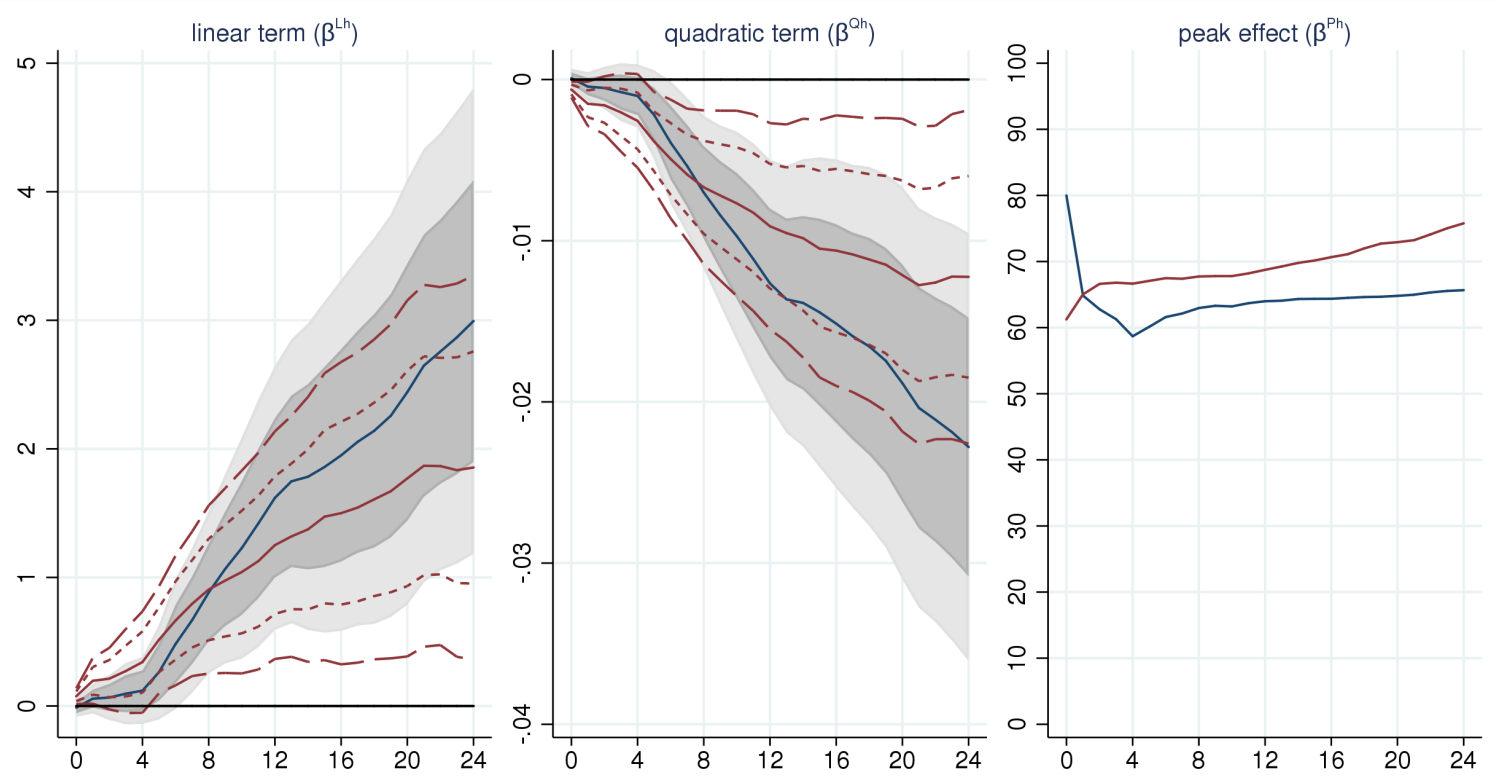

Note. Parameters underlying the quadratic relation between leverage and monetary policy. Blue lines are estimates of equation (1) using daily-frequency identified monetary policy shocks, while red lines are obtained using intraday-frequency identified monetary policy shocks. Bands are $68 \%$ (dark) and $90 \%$ (light) confidence intervals.

positive relation weakens, implying that the most leveraged industries are not necessarily the most responsive ones.

\subsection{Baseline results}

Figure 2 shows the main coefficients of interest from the model in equation (1). ${ }^{15}$ The panel on the left-hand-side reports the coefficient $\beta^{L h}$, which is positive and similarly estimated using the two alternative definitions of shocks. This indicates that, at high levels of capitalization, a higher leverage ratio is generally associated with a greater responsiveness of industrial production to a common monetary policy shock. The middle panel shows the coefficient related to the quadratic term $\beta^{Q h}$, which is negative and, also in this case, robust to different measures of monetary policy shocks. This indicates that the positive association

\footnotetext{
${ }^{15}$ The estimation is carried-out using an unbalanced macro panel consisting of 26667 observations, which account for approximately $99 \%$ of the total number of possible combinations of countries (7), sectors (22), and time periods (175). As explained later, we also check the robustness of our results by estimating the same model using a smaller but balanced macro panel consisting of 23275 observations.
} 
Figure 3. Corporate leverage and monetary policy effectiveness
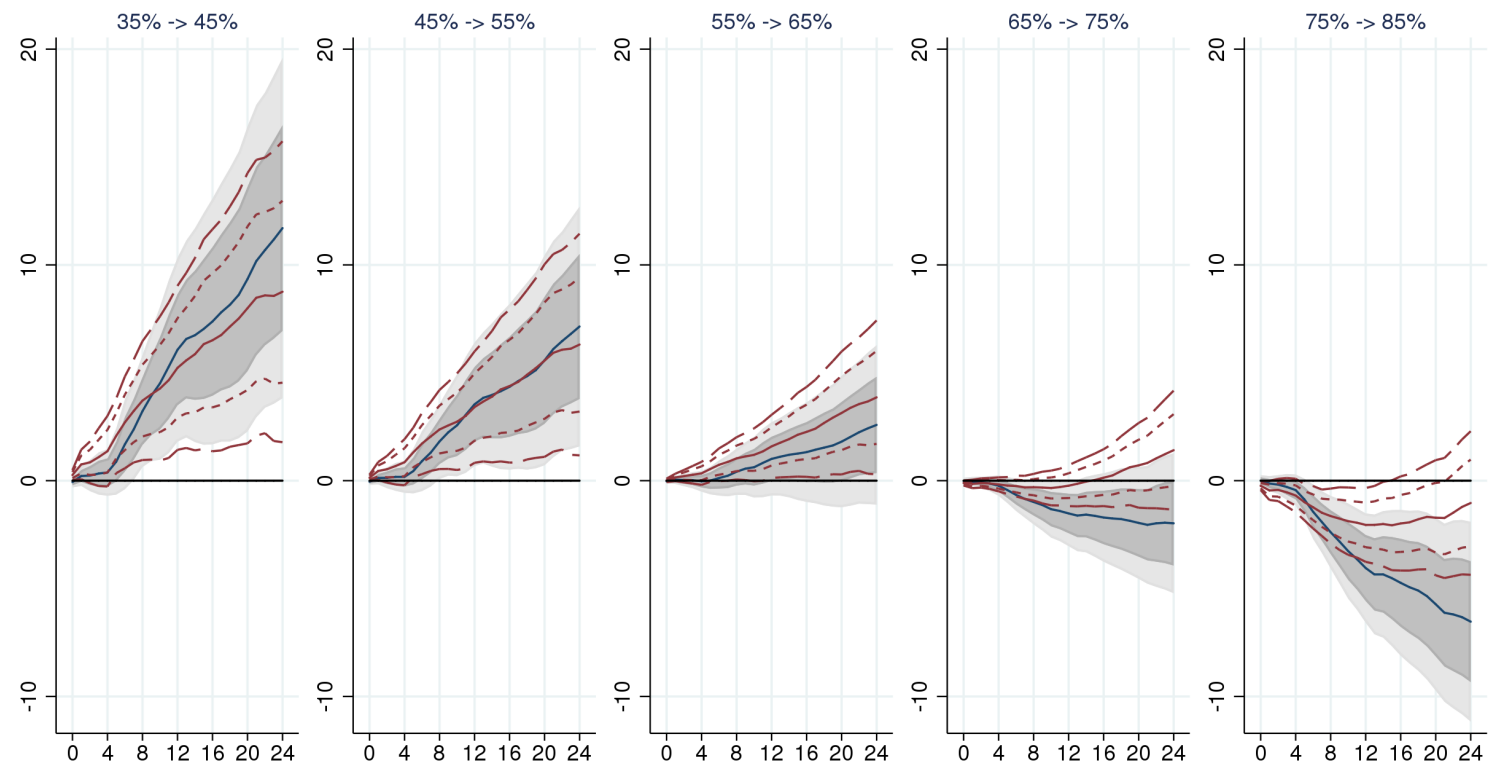

Note. Change in the relative effectiveness of monetary policy associated with a $10 \%$ difference in leverage at several leverage ratios. Blue lines are estimates of equation (1) using daily-frequency identified monetary policy shocks, while red lines are obtained using intraday-frequency identified monetary policy shocks. Bands are $68 \%$ (dark) and $90 \%$ (light) confidence intervals.

between corporate leverage and monetary policy is non-linear and tends to weaken at very high leverage ratios. The panel on the right-hand-side shows that the maximum effect of monetary policy $\beta^{P h}=-1 / 2\left(\beta^{L h} / \beta^{Q h}\right)$ is reached at leverage ratios close to $65 \%-70 \%$.

To offer useful benchmarks for theorist and policymakers, Figure 3 quantifies the differential effect in equation (3) specifying a fixed difference in leverage $(\xi=10 \%)$ and several reference values $(\ell=\{35 \%, \ldots, 75 \%\})$. Our estimates suggest than an industry with a leverage ratio of $75 \%$, despite reacting more strongly than an industry with a leverage ratio of $45 \%$, does not adjust its production more aggressively than an industry with a leverage ratio of $65 \%$.

The baseline findings are robust to several alternative specifications. ${ }^{16}$ For instance, the use of a fully-balanced sample or the specification of shorter samples (ending in 2014 or even 2011) does not significantly alter the results. ${ }^{17}$ The analyzed relation is also robust to

\footnotetext{
${ }^{16}$ The results are available upon request.
}

${ }^{17} \mathrm{~A}$ fully-balanced panel is obtained by excluding the sector "C15 - Manufacture of leather and related 
the specification of a more structural measure of leverage $\tilde{\ell}_{c, s}$, based on the median leverage ratio in each country-industry pair over time.

\subsection{A two-step approach}

We now investigate the unconditional relation between corporate leverage and the effectiveness of monetary policy using an alternative two-step strategy in the spirit of Dedola and Lippi (2005) and Peersman and Smets (2005). In a first step, we estimate the dynamic effect of a common monetary policy shock on the industrial production index for each country-industry pair by means of linear LPs:

$$
\sum_{l=0}^{h} \Delta_{l+1} \ln y_{c, s, t+l}=\alpha_{c, s}^{h}+\beta^{c s h} \varepsilon_{t}+\sum_{p=1}^{12} \theta^{h p} \Delta \ln y_{c, s, t-p}+u_{c, s, t+h}
$$

for $h=0, \ldots, H$. The main coefficient of interest is $\beta^{c s h}$, which measures the cumulative response of industrial production at the horizon $h$ to an expansionary monetary policy shock in each country-industry bin. This gives us 153 cumulative impulse responses over an horizon of $H=24$ months. In a second step, we check the presence of an ex-post relation between the estimated IRFs $\beta_{c, s}^{h}=\left\{\beta^{11 h}, \ldots, \beta^{C S h}\right\}$ and the median leverage ratio $\tilde{\ell}_{c, s}$ in each statistical unit.

The solid lines in Figure 4 depict the cross-sectional averages of the point estimates $\beta_{c, s}^{h}$ at each horizon $h$ using both daily (blue) and intraday (red) shocks. A one-standard deviation expansionary monetary policy shock has on average a positive and persistent effect on industrial production. The size of this effect, as shown by the bands in Figure 4, is however considerably heterogeneous across industries. Given an expansionary monetary policy shock, some industries strongly increase their production, while others barely react to it. We exploit the variation shown in Figure 4 to analyze the ex-post relation between corporate leverage and monetary policy. Before discussing the results, the reader should be

products", due to missing data for Germany in the BACH database, and dropping the sectors "C30 - Manufacture of other transport equipment" and "C33 - Repair and installation of machinery and equipment", due to missing observations in the first years of the sample for Spain and Portugal in the EUROSTAT database. 
Figure 4. Heterogeneous effects of an expansionary monetary policy shock

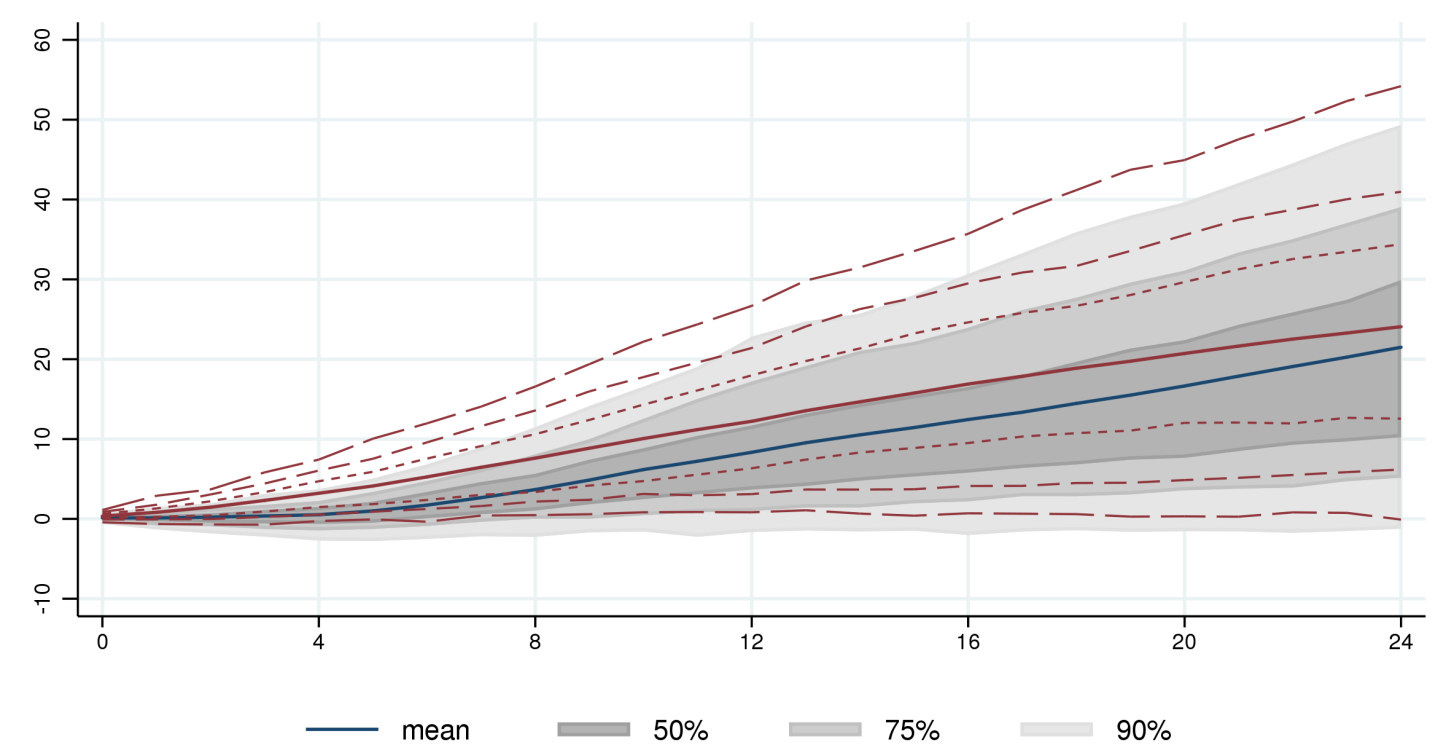

Note. Cross-sectional variation over time of the cumulative effect of an expansionary monetary policy shock on industrial production at the country-industry level using model (4). Blue lines come from daily-frequency identified monetary policy shocks, while red lines are related to intraday-frequency identified monetary policy shocks. Solid lines show the mean of the distribution while the bands show different percentile ranges.

aware that this indirect approach is based on a limited number of observations, coming from an hundred impulse responses at a given horizon $h$. Notwithstanding this limitation, we show that the results from the two-step approach are broadly in line with the ones identified using model (1).

First, we employ a non-parametric approach to analyze the relation between leverage and monetary policy effectiveness. In particular, Figure 5 averages the cumulative IRFs in each tertile of the leverage distribution computing the mean (left-hand-side) and the median (right-hand-side) effects at horizon $h=12$. A concave and non-monotonic pattern, similar to the one identified using the one-step approach, tends to emerge for both daily (blue bars) and intraday (red bars) monetary policy shocks. If we compare the second and the first tertile of the distribution, more leverage tends to be associated with a stronger responsiveness of industrial production to a common monetary policy shock. At very high leverage ratios, however, this relation weakens and more leverage does not necessarily 
Figure 5. Average effect of monetary policy at different leverage tertiles
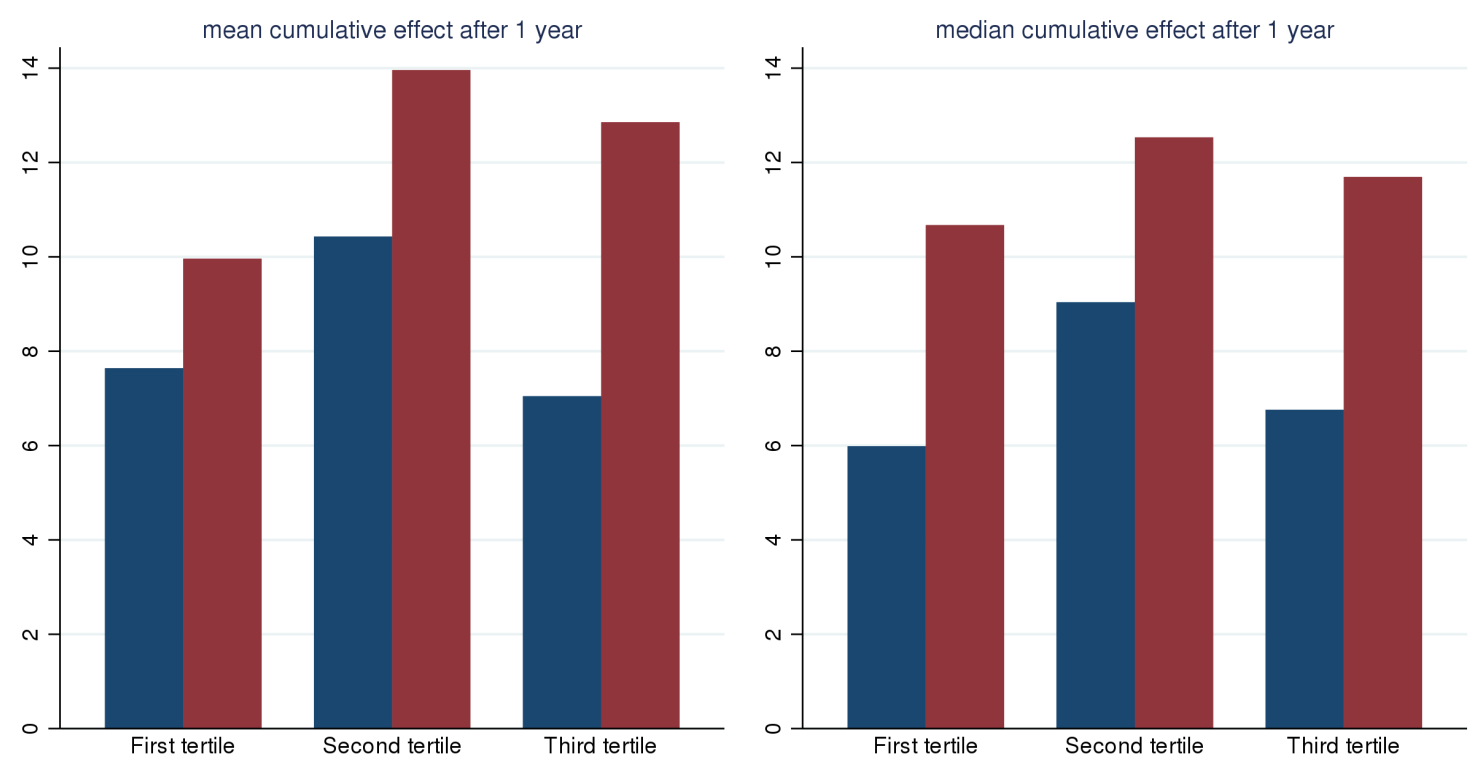

Note. Cumulative effect of a monetary policy shock on industrial production over leverage tertiles after one year. Blue bar are estimates of equation (4) using daily-frequency identified monetary policy shocks, while red bars are obtained using intraday-frequency identified monetary policy shocks.

imply a larger responsiveness to a monetary policy shock (third versus second leverage tertile).

Next, we fit a quadratic relation between the estimated cumulative IRFs and the median leverage ratio in each country-industry bin:

$$
\beta_{c, s}^{h}=\theta^{h}+\gamma^{L h} \tilde{\ell}_{c, s}+\gamma^{Q h} \tilde{\ell}_{c, s}^{2}+\varepsilon_{c, s}^{h}
$$

Columns (1) and (4) in Table 1 confirm the presence of a concave relation between leverage and monetary policy. Interestingly, the peak effect $\gamma^{P h}$ is found to be associated with leverage ratios very close to the ones identified using the one-step approach, that is $63 \%$ and $68 \%$. The main finding does not change meaningfully dropping the minimum and maximum values of the analyzed variables (columns 2-5) or controlling the state-dependent relation for country and industry fixed characteristics (columns 3-6). 
Table 1. Ex-post relation between the estimated effects and leverage

\begin{tabular}{lcccccc}
\hline \hline & $\begin{array}{c}(1) \\
\text { quadratic fit }\end{array}$ & $\begin{array}{c}(2) \\
\mathrm{min} / \mathrm{max}\end{array}$ & $\begin{array}{c}(3) \\
\text { fixed effects }\end{array}$ & $\begin{array}{c}(4) \\
\text { quadratic fit }\end{array}$ & $\begin{array}{c}(5) \\
\mathrm{min} / \mathrm{max}\end{array}$ & $\begin{array}{c}(6) \\
\text { fixed effects }\end{array}$ \\
\hline linear term $\left(\gamma^{L h}\right)$ & 2.34 & 1.96 & 2.39 & 1.67 & 0.91 & 0.93 \\
quadratic term $\left(\gamma^{Q h}\right)$ & -0.02 & -0.02 & -0.02 & -0.01 & -0.01 & -0.01 \\
\hline observations & 153 & 149 & 153 & 153 & 149 & 153 \\
parameters & 3 & 3 & 30 & 3 & 3 & 30 \\
horizon & 12 & 12 & 12 & 12 & 12 & 12 \\
$\begin{array}{l}\text { peak effect }\left(\gamma^{P h}\right) \\
\text { shocks }\end{array}$ & 63 & 64 & 61 & 68 & 75 & 75 \\
\hline \hline
\end{tabular}

Note. Ex-post parametric relation between the estimated cumulative IRFs in each country-industry bin and leverage.

\section{Conclusions}

\section{TO BE DRAFTED}




\section{References}

BACH Working Group, “The Bank for the Accounts of Companies Harmonized (BACH) database," ECB Statistics Paper No. 11, European Central Bank September 2015.

Bernanke, Ben S., Mark Gertler, and Simon Gilchrist, "The Financial Accelerator in a Quantitative Business Cycle Framework," in J. B. Taylor and M. Woodford, eds., Handbook of Macroeconomics, Vol. 1 of Handbook of Macroeconomics, Elsevier, 1999, chapter 21, pp. 1341-1393.

Cecioni, Martina, "ECB Monetary Policy and the Euro Exchange Rate," Bank of Italy Working Paper No. 1172, Bank of Italy April 2018.

Cloyne, James, Clodomiro Ferreira, Maren Froemel, and Paolo Surico, "Monetary Policy, Corporate Finance and Investment," NBER Working Paper No. 25366, National Bureau of Economic Research, Inc December 2018.

Dedola, Luca and Francesco Lippi, "The Monetary Transmission Mechanism: Evidence from the Industries of Five OECD Countries," European Economic Review, August 2005, 49 (6), 1543-1569.

Driscoll, John C. and Aart C. Kraay, "Covariance Matrix Estimation with Spatially Dependent Panel Data," Review of Economics and Statistics, November 1998, 80 (4), 549560.

Gertler, Mark and Peter Karadi, "Monetary Policy Surprises, Credit Costs, and Economic Activity," American Economic Journal: Macroeconomics, January 2015, 7 (1), 44-76.

Gürkaynak, Refet S., Brian Sack, and Eric Swanson, "Do Actions Speak Louder Than Words? The Response of Asset Prices to Monetary Policy Actions and Statements," International Journal of Central Banking, May 2005, 1 (1). 
Jarociński, Marek and Peter Karadi, “Deconstructing Monetary Policy Surprises: the Role of Information Shocks," ECB Working Paper No. 2133, European Central Bank February 2018.

Jeenas, Priit, "Firm Balance Sheet Liquidity, Monetary Policy Shocks, and Investment Dynamics," Working Paper 2019.

Jordá, Óscar, "Estimation and Inference of Impulse Responses by Local Projections," American Economic Review, March 2005, 95 (1), 161-182.

Nakamura, Emi and Jón Steinsson, "High-frequency Identification of Monetary Nonneutrality: the Information Effect," Quarterly Journal of Economics, 2018, 133 (3), 1283-1330.

_ and _ , "Identification in Macroeconomics," Journal of Economic Perspectives, 2018, 32 (3), 59-86.

Ottonello, Pablo and Thomas Winberry, "Financial Heterogeneity and the Investment Channel of Monetary Policy," NBER Working Paper No. 24221, National Bureau of Economic Research, Inc December 2018.

Peersman, Gert and Frank Smets, "The Industry Effects of Monetary Policy in the Euro Area," Economic Journal, April 2005, 115 (503), 319-342. 